\title{
Synthesis and characterization of liquid-crystalline side group polymers with benzylideneaniline as mesogenic moiety
}

\author{
by F. GIESSELMANN and P. ZUGENMAIER \\ Institut für Physikalische Chemie der T.U. Clausthal, D3392 Clausthal-Zellerfeld, \\ F.R. Germany
}

\begin{abstract}
Two new thermotropic liquid-crystalline side group polymers were synthesized, characterized and compared with the liquid-crystalline monomeric analogues. Some packing features of these polymeric liquid crystals are discussed.

Investigations were carried out by differential calorimetry (D.S.C.), polarization microscopic observation and X-ray diffraction on non-aligned and magnetic field-aligned samples in the wide and small angle region.

The synthesized polymers contain as mesogenic moiety a benzylideneaniline group which is attached in the 4 position via a hexamethylene spacer to a polymethacrylate backbone. The benzylideneaniline group is substituted in $4^{\prime}$ position with an ethoxy or butoxy group (PEt or $\mathrm{PBu}$ ). The monomeric analogues are denoted $\mathrm{MEt}$ and $\mathrm{MBu}$. The two polymers show a phase sequence crystallinesmectic A-nematic-isotropic. The liquid-crystalline temperature range is observed between 90 and $150^{\circ} \mathrm{C}$. The monomeric MEt exhibits only a monotropic nematic, $\mathrm{MBu}$ an enantiotropic nematic and a smectic A phase.
\end{abstract}

\section{Introduction}

Liquid-crystalline side group polymers have been widely studied for some time because these compounds should combine the favourable behaviour of liquidcrystalline phases with polymeric properties. However, many problems concerning their physical behaviour have not been solved: the influence of the mesogenic side group on the structure of liquid-crystalline phases, the prediction of phase sequences and a uniform structural model are not yet available. The proposed models depend on the method of investigation, with the placement and role of the main chain not clearly established.

The model evaluation by X-ray methods suffers from limited data even in the crystalline state, because of the poorly developed long range order for some side group polyacrylate and polymethacrylate. Comparative studies of very different systems in a systematic way might lead to progress in solving the structural problems. The synthesis of new types of side group polymers appears to be a necessity and should result in materials with various phase sequences.

In low molar mass liquid crystals the benzylideneaniline group belongs to the oldest and most widely used mesogenic moiety and shows a large variety of mesomorphy. However, this mesogenic group was not fully exploited as a side group in polymeric liquid crystals. In the beginning of the development of liquid crystal side group polymers, alkyl and alkoxy substituted benzylideneaniline was attached without a spacer to a polyacrylate and polymethacrylate backbone [1] and poor mesophase behaviour was detected. An $\mathrm{S}_{\mathrm{A}}$ phase was obtained for carboxyl substituted benzylideneaniline bound without a spacer to a polymethacrylate chain [2]. After introduction of the spacer concept, better phase behaviour was observed. A nitrile [3] and butyl [4] substituted benzylideneaniline was fixed with spacers of 6 and 11 
methylene groups $\left(\mathrm{C}_{6}\right.$ and $\left.\mathrm{C}_{11}\right)$ to a polyacrylate and polymethacrylate main chain and led to $S_{A}$ and $S_{C}$ phases for the nitrile-substituted mesogen and to $S_{A}$ and $S_{B}$ phases with the butyl-substituted one and a spacer length of $\mathrm{C}_{11}$ for both polymers.

As a continuation of this work, the alkoxy substituted benzylideneanilines were synthesized for a comparative study of monomeric and polymeric liquid crystals. The mesogenic group was attached by a hexamethylene spacer to a polymethyacrylate chain. The polarity of the alkoxy group lies between the nitrile and butyl group and might cause a different phase sequence not yet observed with this side group mesogen.

\section{Experimental}

New compounds (see figure 1) were synthesized according to well known methods. The reaction paths are given in figure 2 and documented in [5]. An elementary analysis was performed by the microanalytic laboratory Beller in Göttingen, and the results are listed in Table 1.

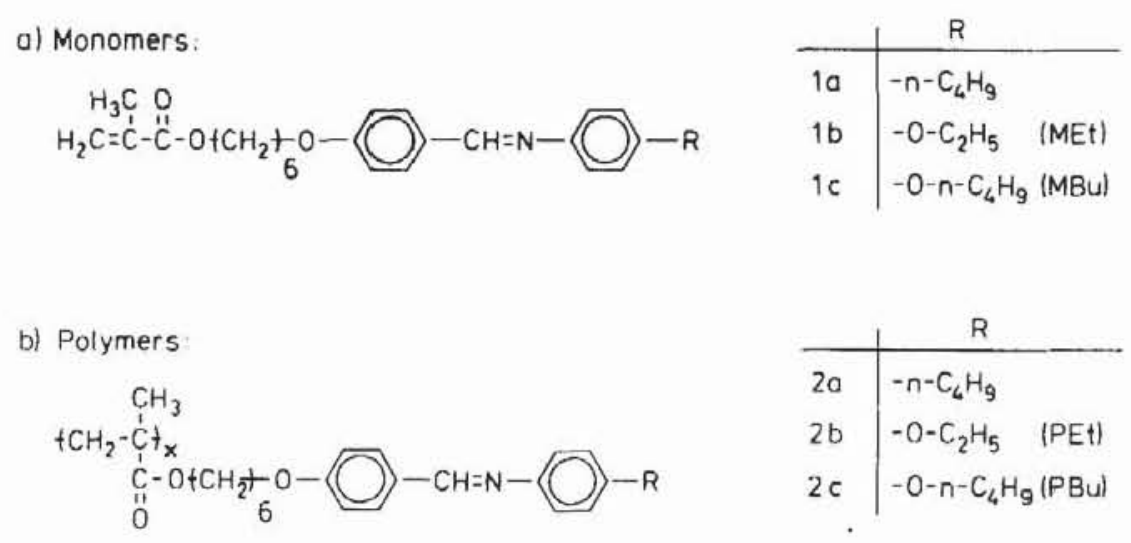

Figure 1. Monomeric and polymeric compounds synthesized, abbreviations with regard to the terminal group of the mesogenic moiety $(\mathrm{M}$, monomer; $\mathrm{P}$, polymer) and numbering.

Table 1. Elementary analysis of the compounds investigated. The calculated values are listed in parentheses.

\begin{tabular}{lccc}
\hline Compound & C/per cent & H/per cent & N/per cent \\
\hline MEt & $73.38(73.32)$ & $7.67(7.63)$ & $3.55(3.42)$ \\
MBu & $73.36(74 \cdot 11)$ & $8.10(8.06)$ & $3.25(3.20)$ \\
PEt & $73.27(73.32)$ & $7.55(7.63)$ & $3.40(3.42)$ \\
PBu & $73.37(74 \cdot 11)$ & $8.17(8.06)$ & $3.29(3.20)$ \\
\hline
\end{tabular}

Polarization microscopic investigations were carried out with an Olympus BH-2 microscope equipped with a hot stage of Mettler FP 800 . Since characteristic textures were obtained more easily on cooling from the isotropic melt, the samples were melted on a glass plate and covered with a second glass plate, and air bubbles were removed through a light pressure on the cover slide.

Nickel-filtered $\mathrm{Cu}-K_{\alpha}$ radiation was used for X-ray studies in a vacuum flat film and Kratky compact camera, both equipped with electrically heated sample holders. A magnetic field perpendicular to the X-ray beam was available in the flat film camera [6]. Two temperature resistant permanent magnets at a distance of $1.5 \mathrm{~mm}$ created a 

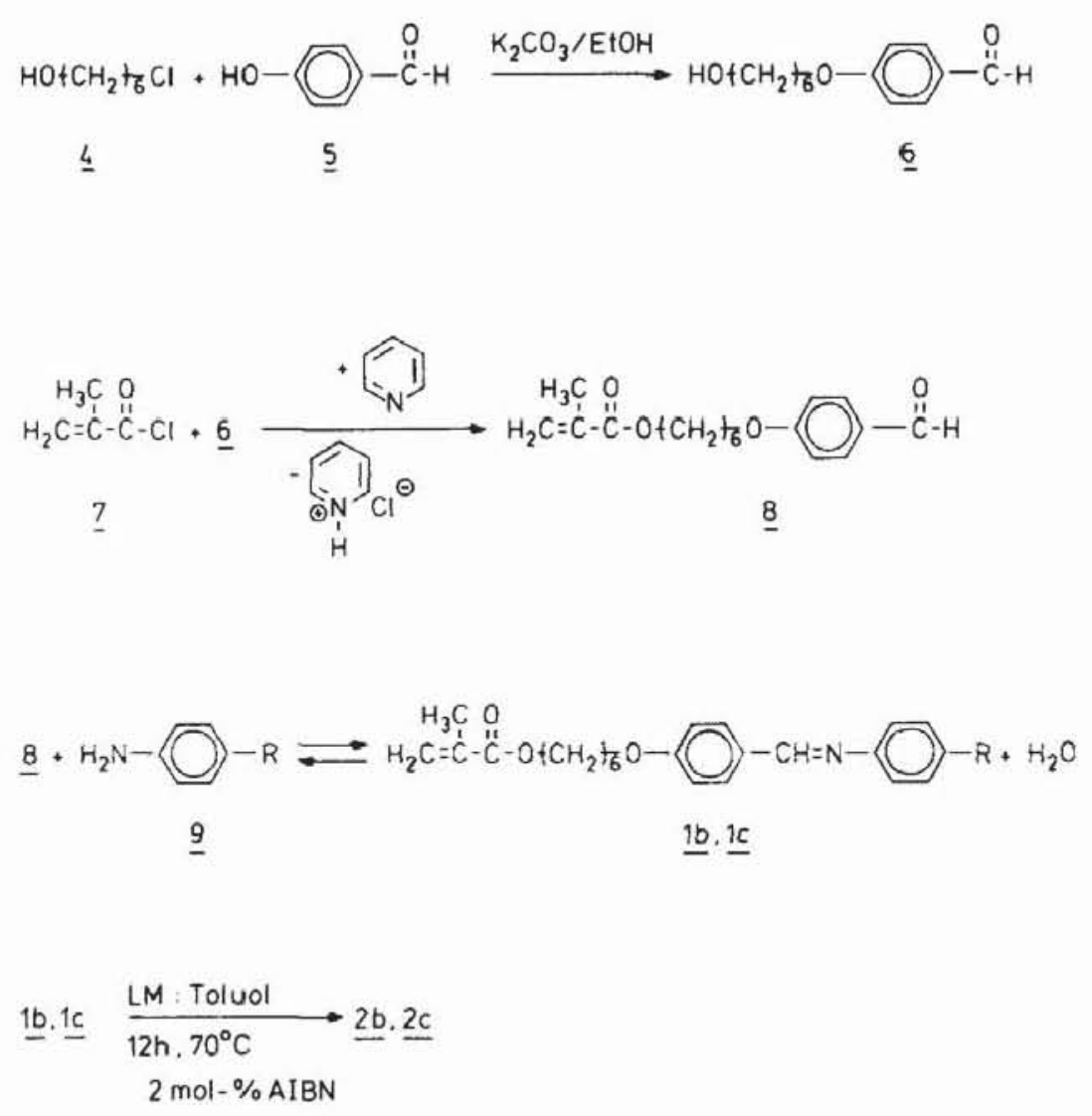

Figure 2. Pathway of synthesis for the compounds investigated.

magnetic flux of $0.9 \mathrm{~T}$. The sampie was placed in a Mark capillary and X-ray exposures were taken upon cooling from the isotropic melt for the samples in the mesophases. The Kratky camera with a position-sensitive counter (Firma Braun, Munich, F.R. Germany) served for studies of $d$-spacings in the small angle region of non-aligned samples. In contrast with the flat film exposures, the measurements were performed upon heating. The thermal investigations were carried out with a PerkinElmer D.S.C.-7 apparatus and the onset and peak temperatures were taken, listed and discussed.

\section{Results and discussion}

\subsection{Monomers}

The monomers MEt (1) and MBu (1c) (cf. figure 1) differ little in their chemical constitution but show quite different phase behaviour. Only a monotropic, nematic mesophase is detected for MEt and appears between 85 and $74^{\circ} \mathrm{C}$ in the polarization microscope, mostly as pseudo-isotropic phase, upon cooling. Observations in the conoscopic mode reveal a uniaxial, optically positive structure. Occasionally a Schlieren-texture was obtained as represented in figure 3 , which was difficult to reproduce.

The X-ray pattern (see figure 4) of a magnetic field-aligned nematic sample oi MEt shows, besides an equatorial halo with $d=4.5 \AA$, a weak and diffuse meridional reflection at $d=28.0 \AA$, which can be clearly distinguished from the sharp layer reflections of smectic phases. The third order of this reflection with $d=9 \cdot 3 \AA$ is still observable. 


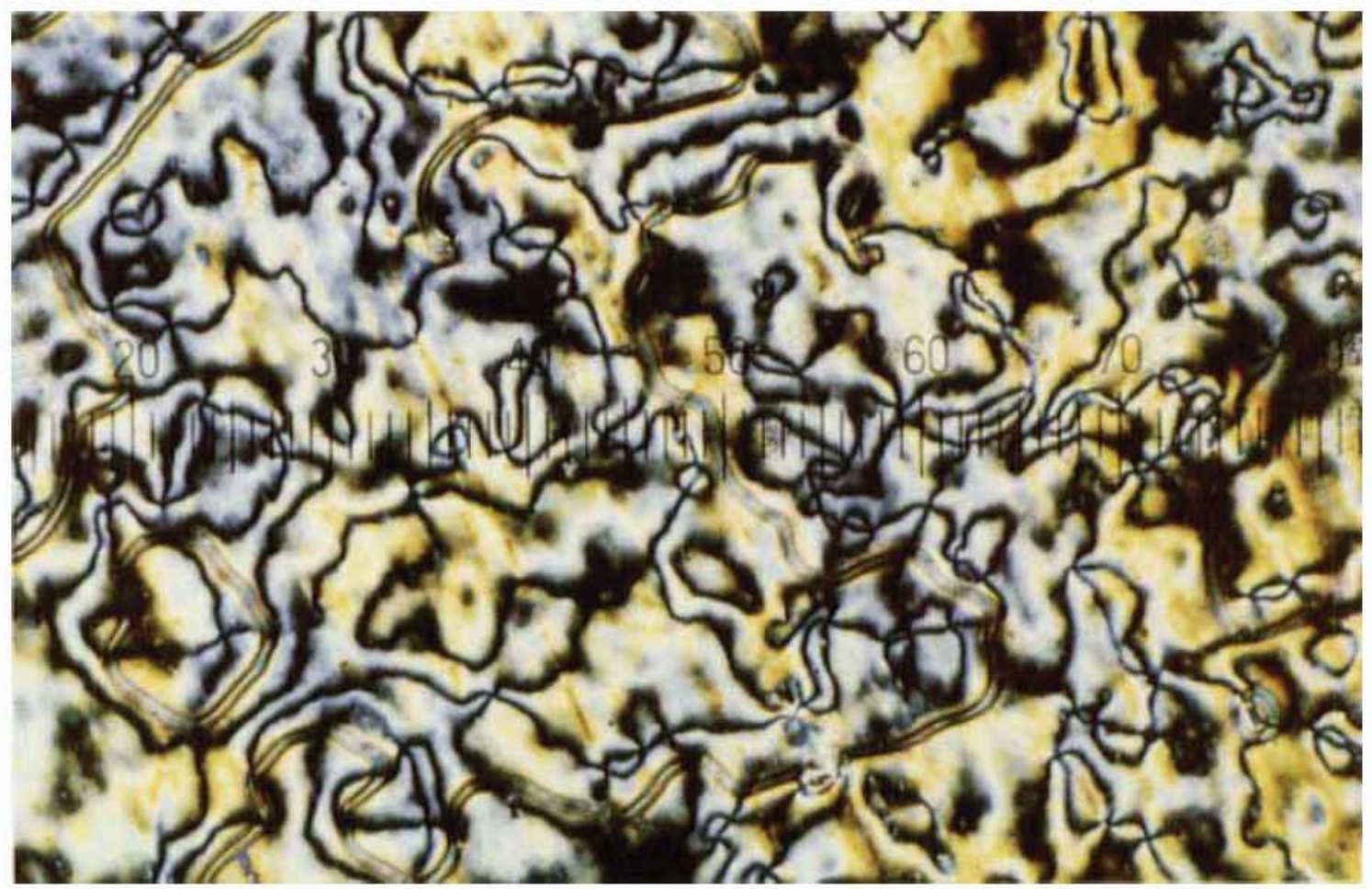

Figure 3. Nematic Schlieren-texture of MEt observed between crossed polars in the microscope $(\times 100)$ at $78 \cdot 1^{\circ} \mathrm{C}$.

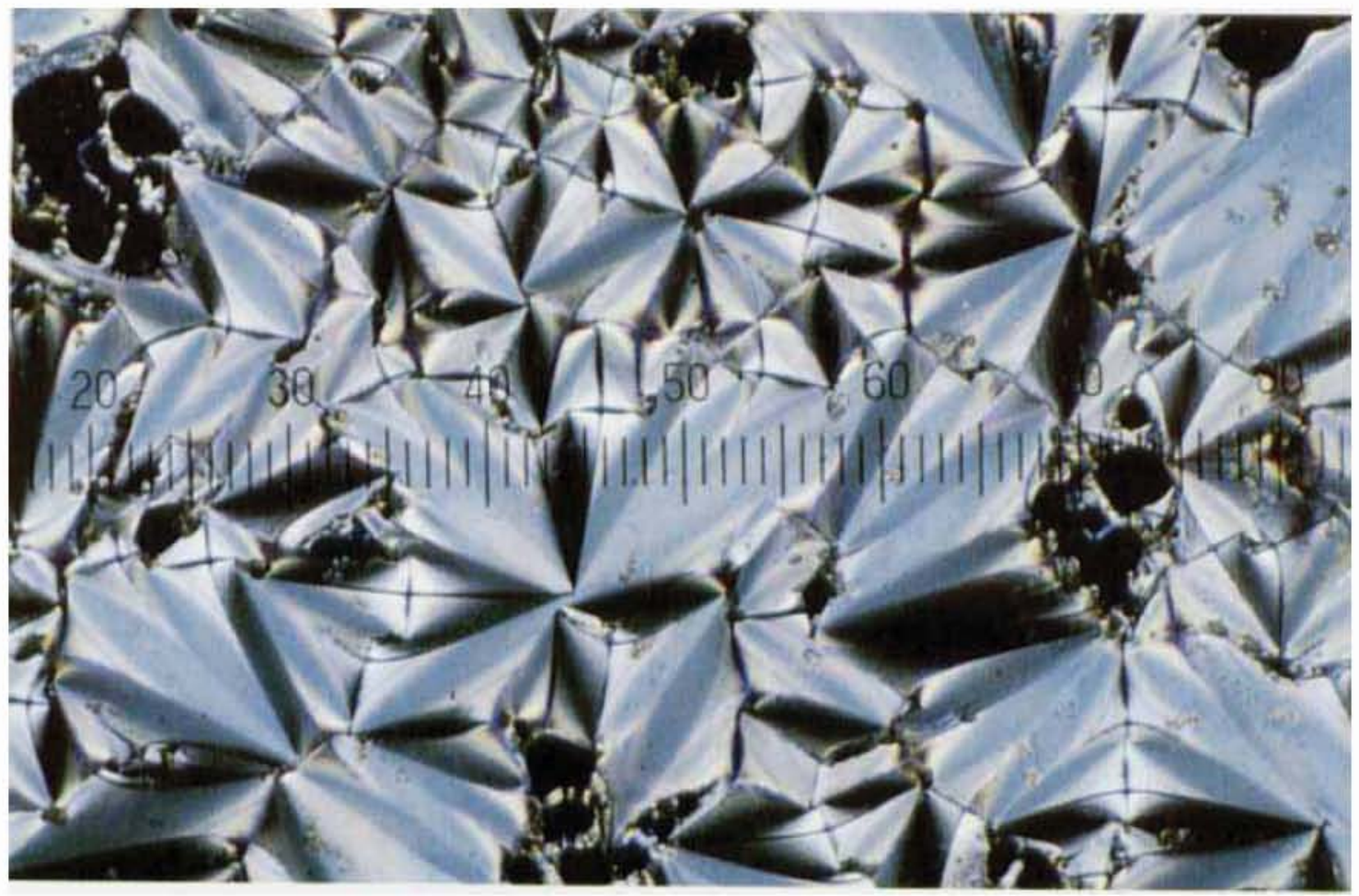

Figure 6. Fan-shaped texture of smectic A phase for MBu observed between crossed polars in the microscope $(\times 270)$ at $76 \cdot 3^{\circ} \mathrm{C}$. 


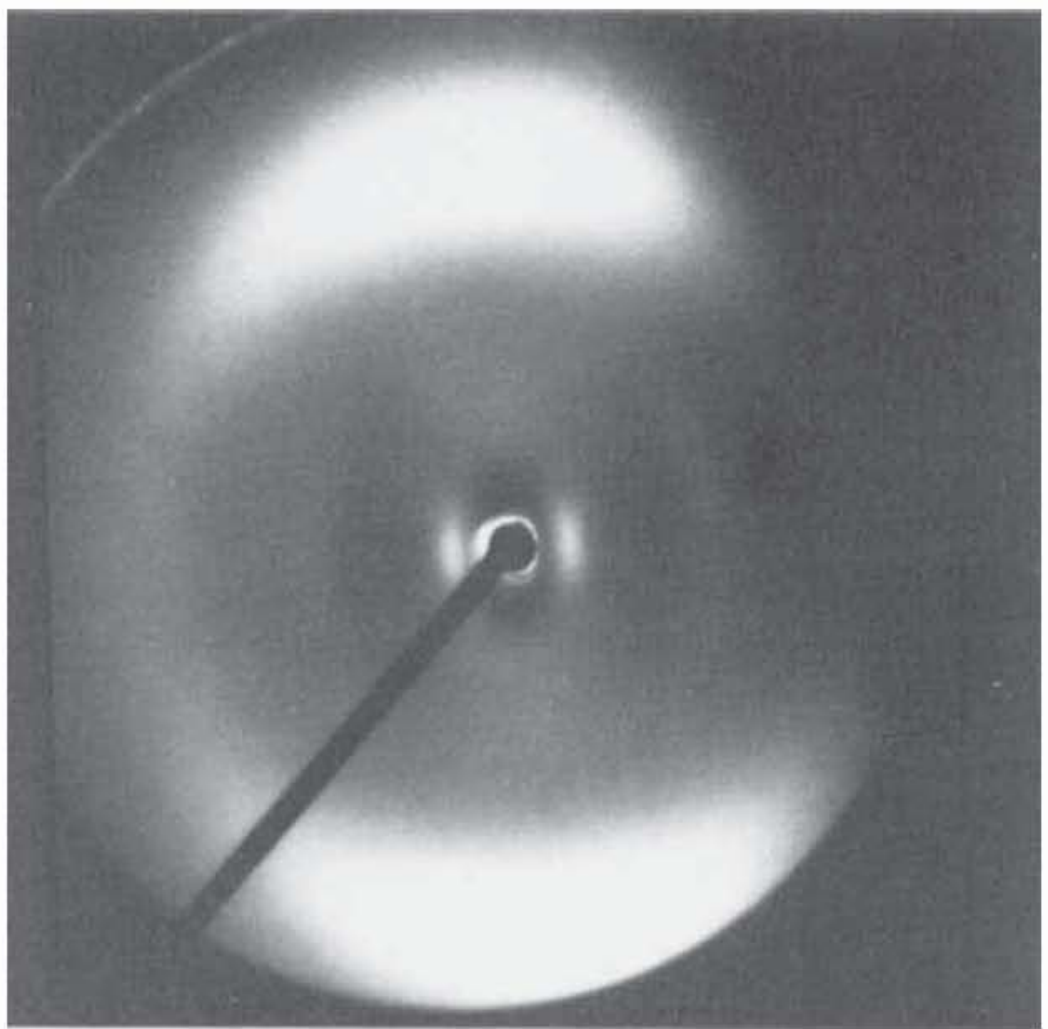

Figure 4. X-ray pattern of the nematic sample of MEt oriented in a magnetic field at $80^{\circ} \mathrm{C}$. The magnetic field direction is perpendicular to the X-ray beam, and is placed horizontal in this representation. It also represents the fibre axis of this X-ray exposure.

The D.S.C. measurements confirm the monotropy of the phase behaviour of MEt (see figure 5). It is noteworthy that the isotropic-nematic transition at $79.7^{\circ} \mathrm{C}$ in D.S.C. measurements is about $5^{\circ} \mathrm{C}$ lower then by polarization microscopic observations. The sample seems to be very sensitive to the preparation methods. The phase transition temperature was determined for a homeotropic oriented sample in the polarization microscope and for an unoriented sample in the D.S.C. apparatus, and therefore should not be compared.

Table 2. Phase behaviour of the compounds investigated derived from polarization microscopic observation (temperatures listed in ${ }^{\circ} \mathrm{C}$ ).

\begin{tabular}{|c|c|c|c|c|c|c|c|c|}
\hline Compound & & $\mathrm{K}$ & & $\mathrm{S}_{\mathrm{A}}$ & & $\mathrm{N}$ & & I \\
\hline ME & $\begin{array}{l}\text { Heating } \\
\text { Cooling }\end{array}$ & $\bullet$ & $\begin{array}{c}82-85 \\
74 \cdot 1\end{array}$ & - & & - & $84 \cdot 8$ & $\bullet$ \\
\hline $\mathrm{MBu}$ & $\begin{array}{l}\text { Heating } \\
\text { Cooling }\end{array}$ & $\bullet$ & $\begin{array}{l}74 \cdot 3 \\
55 \cdot 9\end{array}$ & $\bullet$ & $\begin{array}{l}78 \cdot 5 \\
78 \cdot 2\end{array}$ & $\bullet$ & $\begin{array}{l}82 \cdot 2 \\
82 \cdot 2\end{array}$ & $\bullet$ \\
\hline PEt & $\begin{array}{l}\text { Heating } \\
\text { Cooling }\end{array}$ & - & $\begin{array}{l}88 \cdot 2 \\
90 \cdot 1\end{array}$ & $\bullet$ & $\begin{array}{l}127 \cdot 6 \\
127 \cdot 2\end{array}$ & $\bullet$ & $\begin{array}{l}151 \cdot 7 \\
150 \cdot 6\end{array}$ & 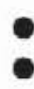 \\
\hline $\mathrm{PBu}$ & $\begin{array}{l}\text { Heating } \\
\text { Cooling }\end{array}$ & - & $\begin{array}{l}97.8 \\
96.0\end{array}$ & - & $\begin{array}{l}130 \cdot 9 \\
132 \cdot 3\end{array}$ & - & $\begin{array}{l}136 \cdot 8 \\
137 \cdot 2\end{array}$ & - \\
\hline
\end{tabular}

The monomeric compound $\mathrm{MBu}$ shows a more complex phase behaviour than MEt (see table 2). A nematic and $S_{A}$ mesophase are observed besides several crystalline modifications. The nematic phase appears as a homeotropic, uniaxial and 


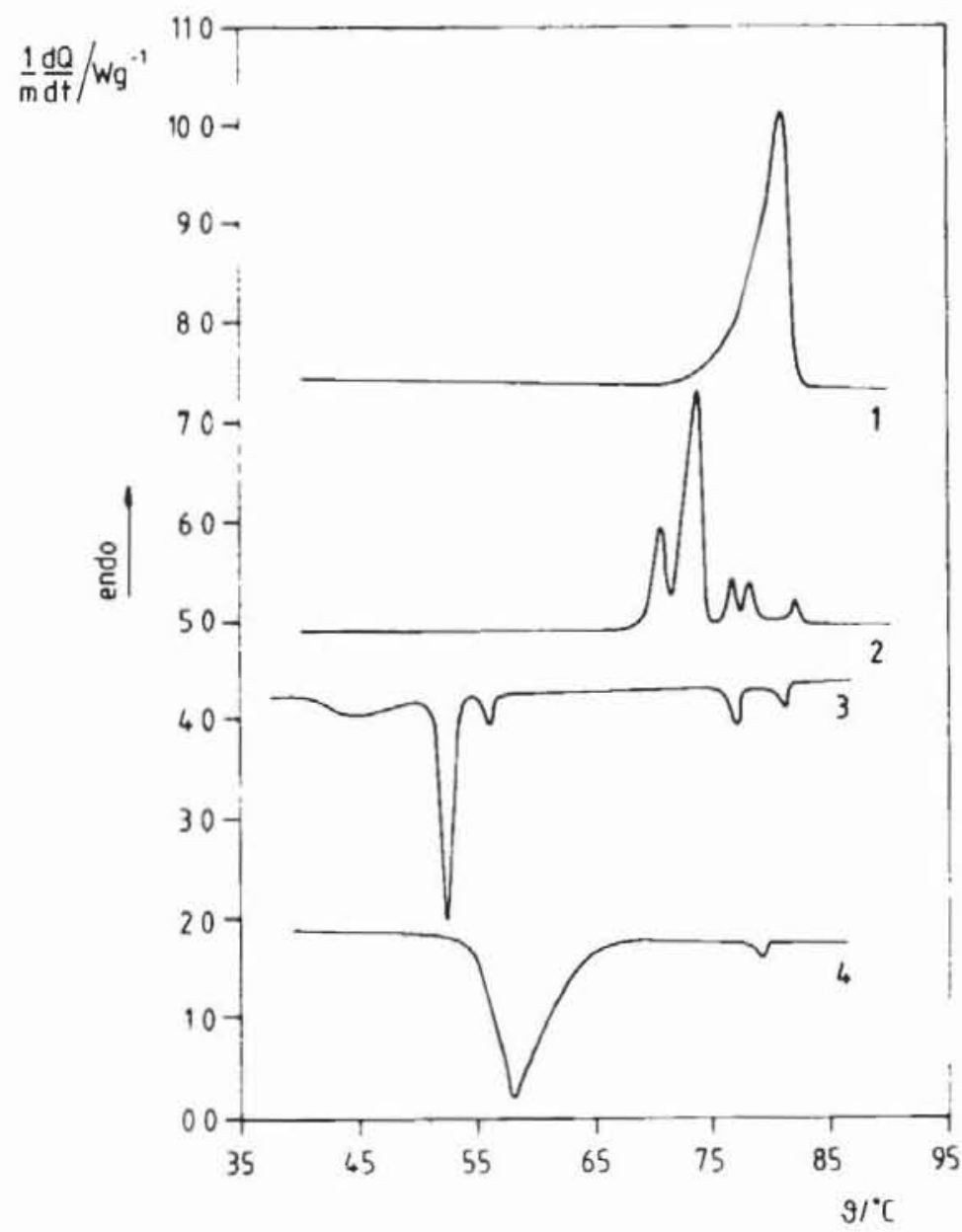

Figure 5. Normalized D.S.C. curves of the monomeric samples of MEt and MBu. 1, MEt upon heatıng of $5^{\circ} \mathrm{C} \min ^{-1} ; 2, \mathrm{MBu}$ upon heatıng at $5^{\circ} \mathrm{C} \min ^{-1} ; 3, \mathrm{MBu}$ upon cooling of $5^{\circ} \mathrm{C} \mathrm{min}^{-1}, 4, \mathrm{MEt}$ upon cooling at $5^{\circ} \mathrm{C} \mathrm{m}^{-1}$.

Table 3. Temperature and enthalpy of phase transitions of the monomers MEt and MBu from D.S.C. measurements.

\begin{tabular}{|c|c|c|c|c|}
\hline Compound & $\ni_{\text {onset }} /{ }^{\circ} \mathrm{C}$ & $\vartheta_{\text {peak }} /{ }^{\circ} \mathrm{C}$ & $\Delta H / \mathrm{Jg}^{-1}$ & Remarks \\
\hline $\begin{array}{l}\mathrm{MEt} \\
\mathrm{MEt} \\
\mathrm{MEt}\end{array}$ & $\begin{array}{l}77 \cdot 3 \\
79 \cdot 6 \\
61 \cdot 3\end{array}$ & $\begin{array}{l}81 \cdot 1 \\
79 \cdot 3 \\
58 \cdot 1\end{array}$ & $\begin{array}{r}116.7 \\
-2 \cdot 1 \\
-100 \cdot 6\end{array}$ & 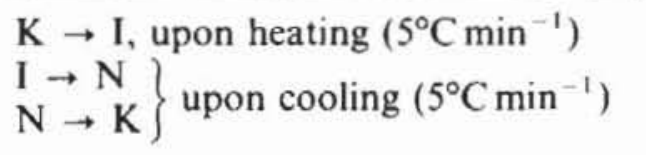 \\
\hline $\begin{array}{l}\mathrm{MBu} \\
\mathrm{MBu} \\
\mathrm{MBu} \\
\mathrm{MBu} \\
\mathrm{MBu}\end{array}$ & $\begin{array}{l}69 \cdot 5 \\
71 \cdot 7 \\
76 \cdot 0 \\
77 \cdot 6 \\
81 \cdot 7\end{array}$ & $\begin{array}{l}70 \cdot 7 \\
73 \cdot 7 \\
76 \cdot 7 \\
78 \cdot 2 \\
82 \cdot 2\end{array}$ & $\begin{array}{r}62 \cdot 9 \\
4 \cdot 7 \\
3 \cdot 9 \\
1 \cdot 8\end{array}$ & $\left.\begin{array}{l}\mathrm{K}_{1} \rightarrow \mathrm{K}_{2} \\
\mathrm{~K}_{2} \rightarrow \mathrm{K}_{3} \\
\mathrm{~K}_{3} \rightarrow \mathrm{S}_{\mathrm{A}} \\
\mathrm{S}_{\mathrm{A}} \rightarrow \mathrm{N} \\
\mathrm{N} \rightarrow \mathrm{I}\end{array}\right\}$ upon heating $\left(5^{\circ} \mathrm{Cmin}^{-1}\right)$ \\
\hline $\begin{array}{l}\mathrm{MBu} \\
\mathrm{MBu} \\
\mathrm{MBu} \\
\mathrm{MBu} \\
\mathrm{MBu}\end{array}$ & $\begin{array}{l}81 \cdot 6 \\
77 \cdot 6 \\
56 \cdot 5 \\
53 \cdot 3 \\
48 \cdot 5\end{array}$ & $\begin{array}{l}81 \cdot 2 \\
77 \cdot 1 \\
56 \cdot 0 \\
52 \cdot 4 \\
45 \cdot 0\end{array}$ & $\begin{array}{r}-1.9 \\
-3 \cdot 9 \\
-3 \cdot 4 \\
-50 \cdot 0\end{array}$ & $\left.\begin{array}{l}\mathrm{I} \rightarrow \mathrm{N} \\
\mathrm{N} \rightarrow \mathrm{S}_{\mathrm{A}} \\
\mathrm{S}_{\mathrm{A}} \rightarrow \mathrm{K}_{3} \\
\mathrm{~K}_{3} \rightarrow \mathrm{K}_{2} \\
\mathrm{~K}_{2} \rightarrow \mathrm{K}_{1}\end{array}\right\}$ upon cooling $\left(5^{\circ} \mathrm{C} \mathrm{min}^{-1}\right)$ \\
\hline
\end{tabular}

optically positive structure, when prepared between two cover slides, as described for MEt. This phase shows the same X-ray pattern characteristic for the MEt compound. The $S_{A}$ phase exhibits a focal-conic fan-like texture in the polarization microscope (see figure 6). 


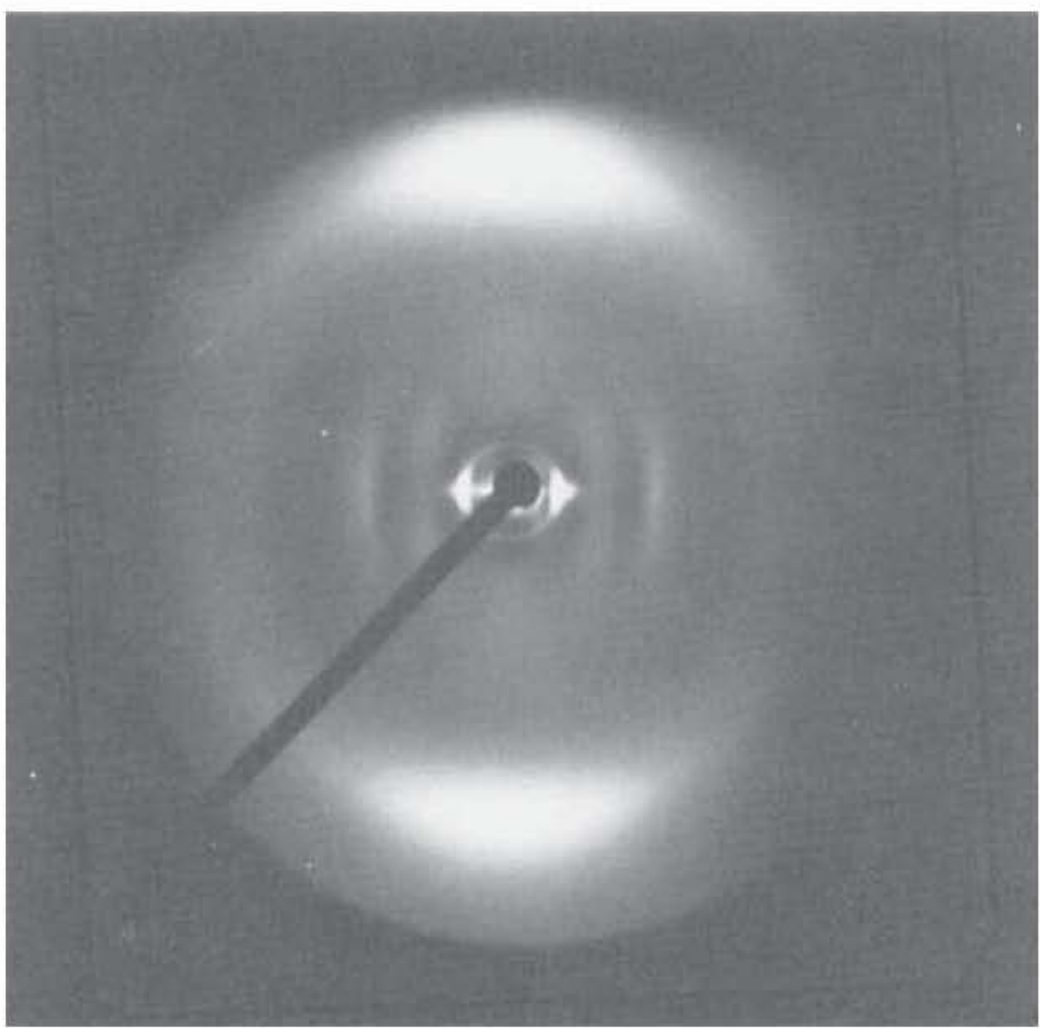

Figure 7. X-ray pattern of a smectic A sample of $\mathrm{MBu}$ oriented in a magnetic field at $76^{\circ} \mathrm{C}$. The magnetic field direction is perpendicular to the X-ray beam, and is placed horizontal in this representation.

The X-ray pattern of a magnetic field-aligned smectic sample shows the characteristic features of an $S_{A}$ phase (see figure 7): a diffuse equatorial halo and sharp meridional layer reflections with $d=30.5 \AA$, and small second and third order reflections thereof.

The significant difference between the diffuse meridional reflections of the nematic phase and the sharp smectic layer reflections of the $\mathrm{S}_{\mathrm{A}}$ phase is best demonstrated in a Kratky diagram (see figures 8 and 9).

Further phase transitions are detected by D.S.C. below the $S_{A}$ phase (figure 5), mostly crystalline-crystalline transitions. The $\mathrm{S}_{\mathrm{A}}$ neighbouring phase, termed $\mathrm{K}_{3}$ in table 3 , and whose Kratky X-ray diagram is represented in figure 10, shows a texture similar to a highly ordered smectic phase (see figure 11). The Kratky plot looks very simple, with sharp reflections of $d=26 \cdot 55 \AA$, well below the size of the extended molecule, and some higher orders which agree with a tilted smectic phase. X-ray exposures of oriented samples have not yet been obtained, and since no macroscopic mobility of the sample was observed the phase was denoted as crystalline.

The two monomeric compounds, $\mathrm{MEt}$ and $\mathrm{MBu}$, are difficult to interpret with regard to thermal analysis (see figure 5 and table 3 ). Not only do the transition temperatures determined by D.S.C. differ from those observed in the polarization microscope, but differences are also encountered for corresponding enthalpies upon heating and cooling for the same phase transition.

\subsection{Polymers}

The two polymeric compounds, PEt and PBu, lead to the same sequence of phases, in contrast with their corresponding monomeric analogues (see table 2 ). The nematic 


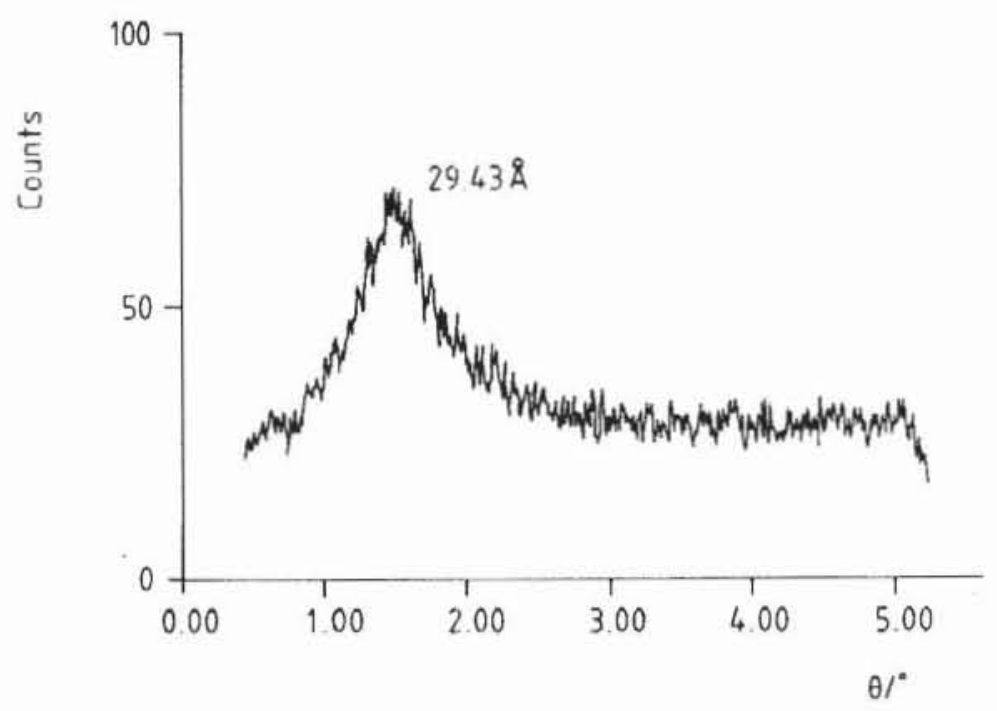

Figure 8. Kratky plot of the non-aligned nematic phase of $\mathrm{MBu}$ at $82^{\circ} \mathrm{C}$ (counting time $300 \mathrm{~s}$ ).

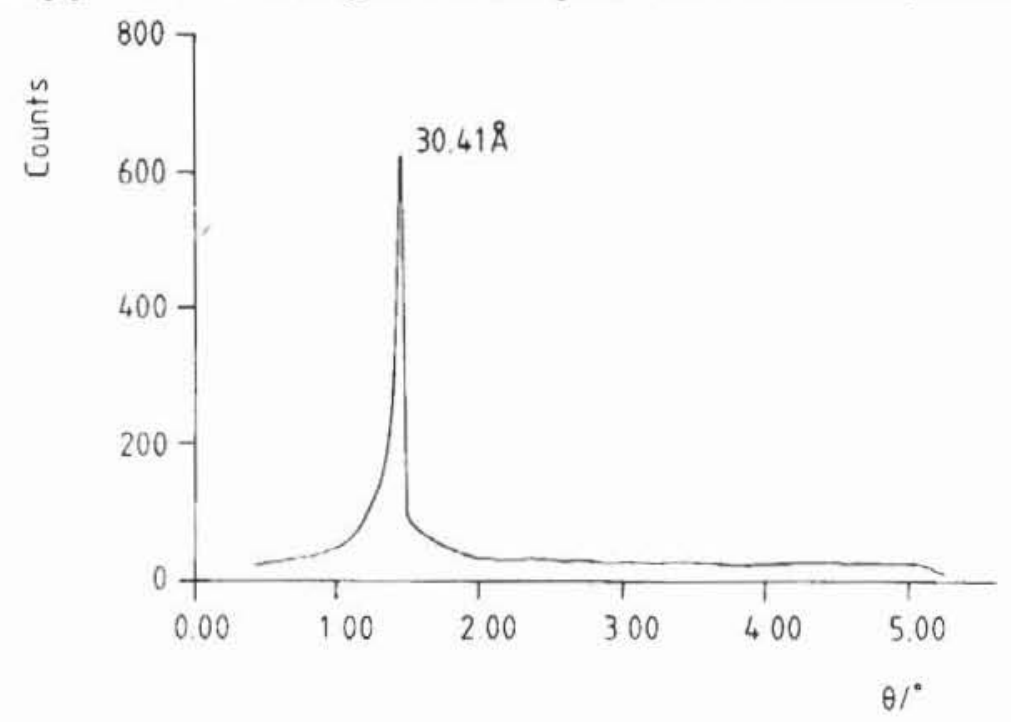

Figure 9. Kratky plot of the non-aligned smectic A phase of $\mathrm{MBu}$ at $79^{\circ} \mathrm{C}$ (counting time $300 \mathrm{~s}$ ).

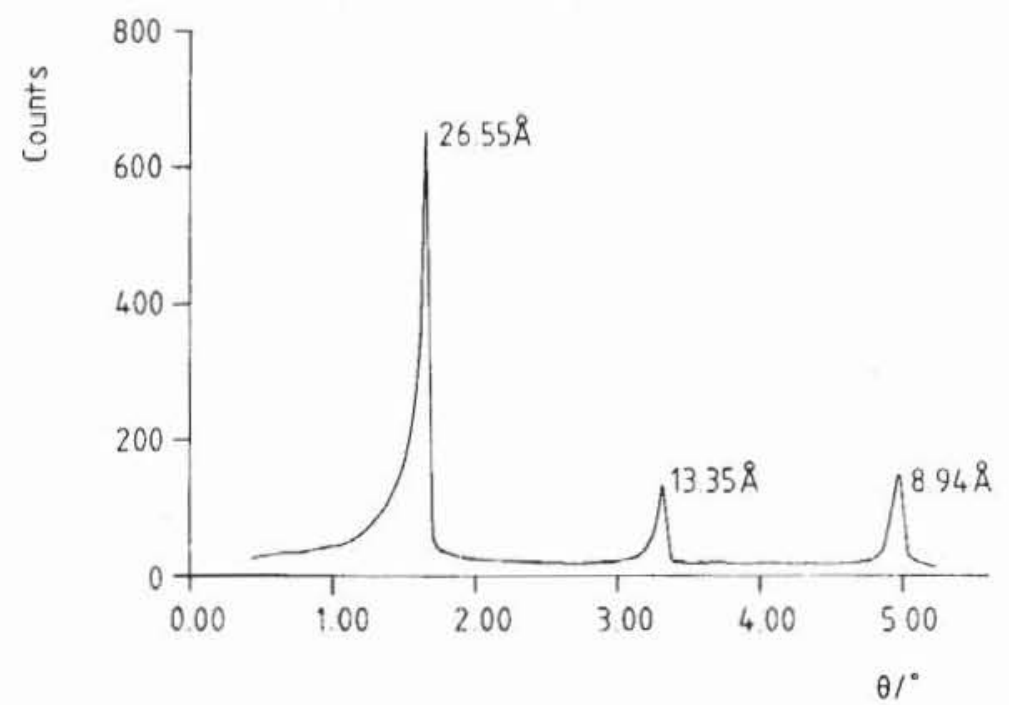

Figure 10. Kratky plot of the non-aligned probable crystalline phase of $\mathrm{MBu}$ at $75^{\circ} \mathrm{C}$ (counting time $300 \mathrm{~s}$ ). 


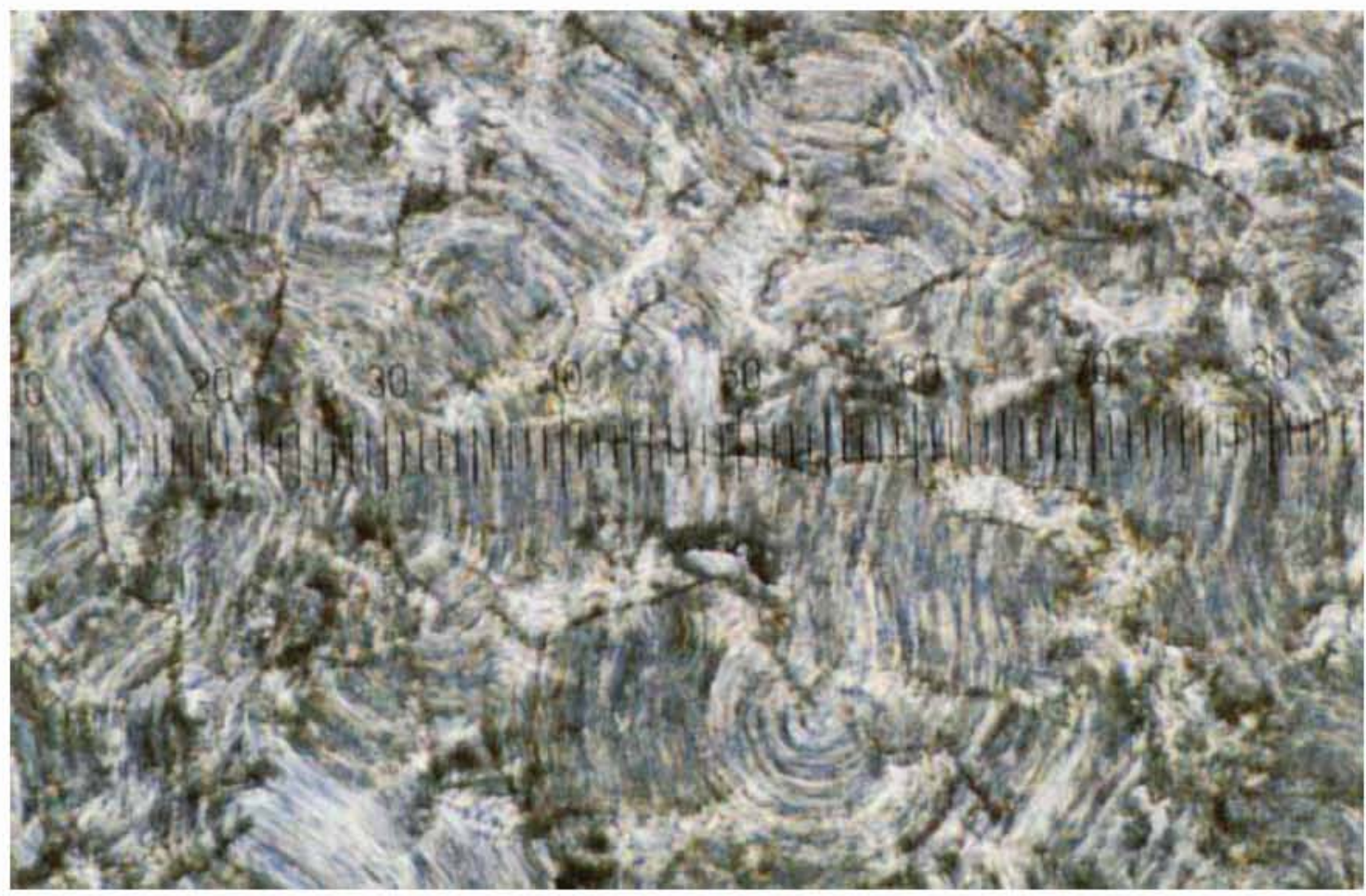

Figure 11. Probable crystalline texture of $\mathrm{MBu}$ observed between crossed polars in the microscope $(\times 200)$ at $52^{\circ} \mathrm{C}$.

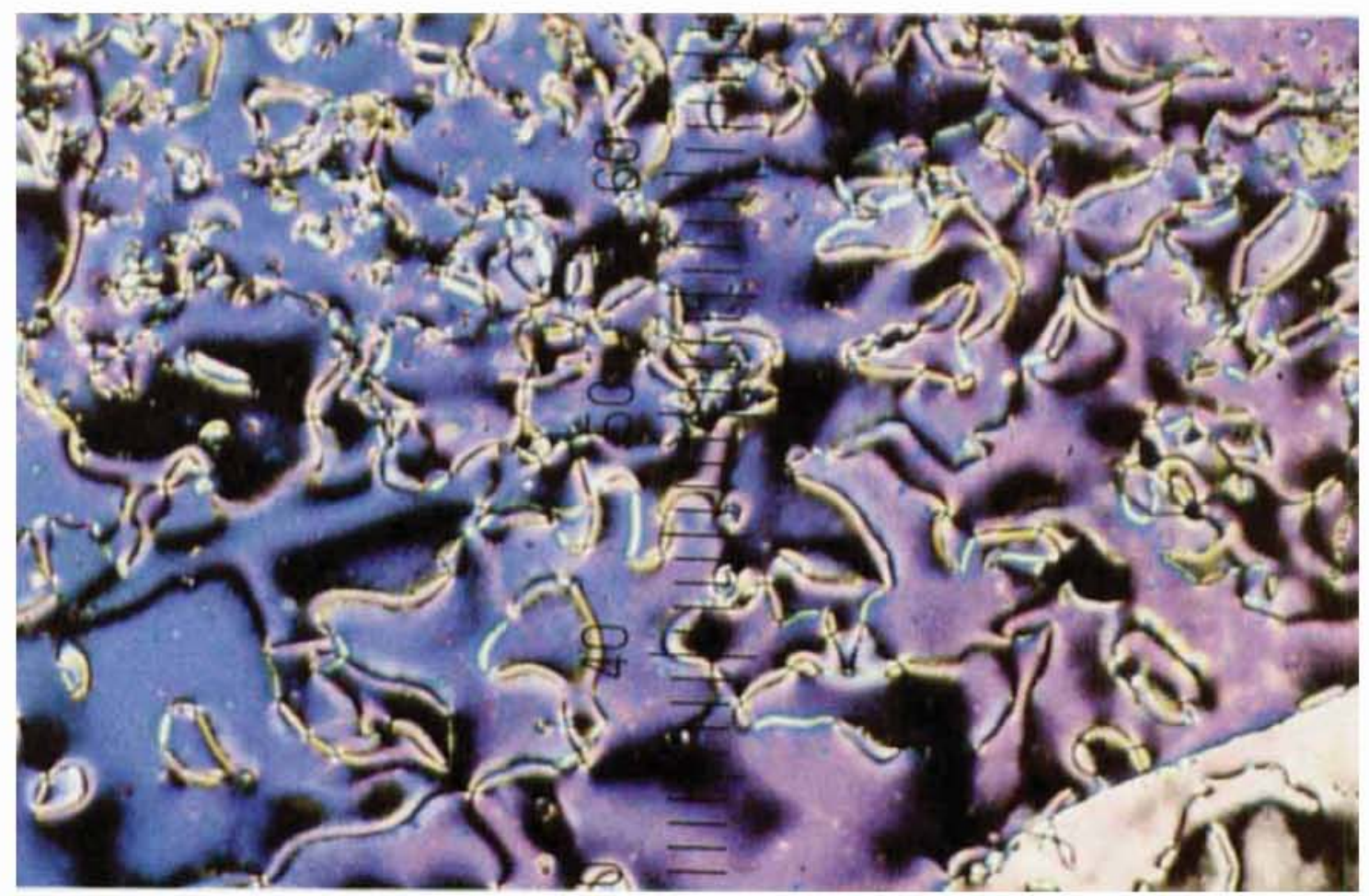

Figure 12. Nematic Schlieren-texture of PEt observed between crossed polars in the microscope $(\times 160)$ at $135^{\circ} \mathrm{C}$. 


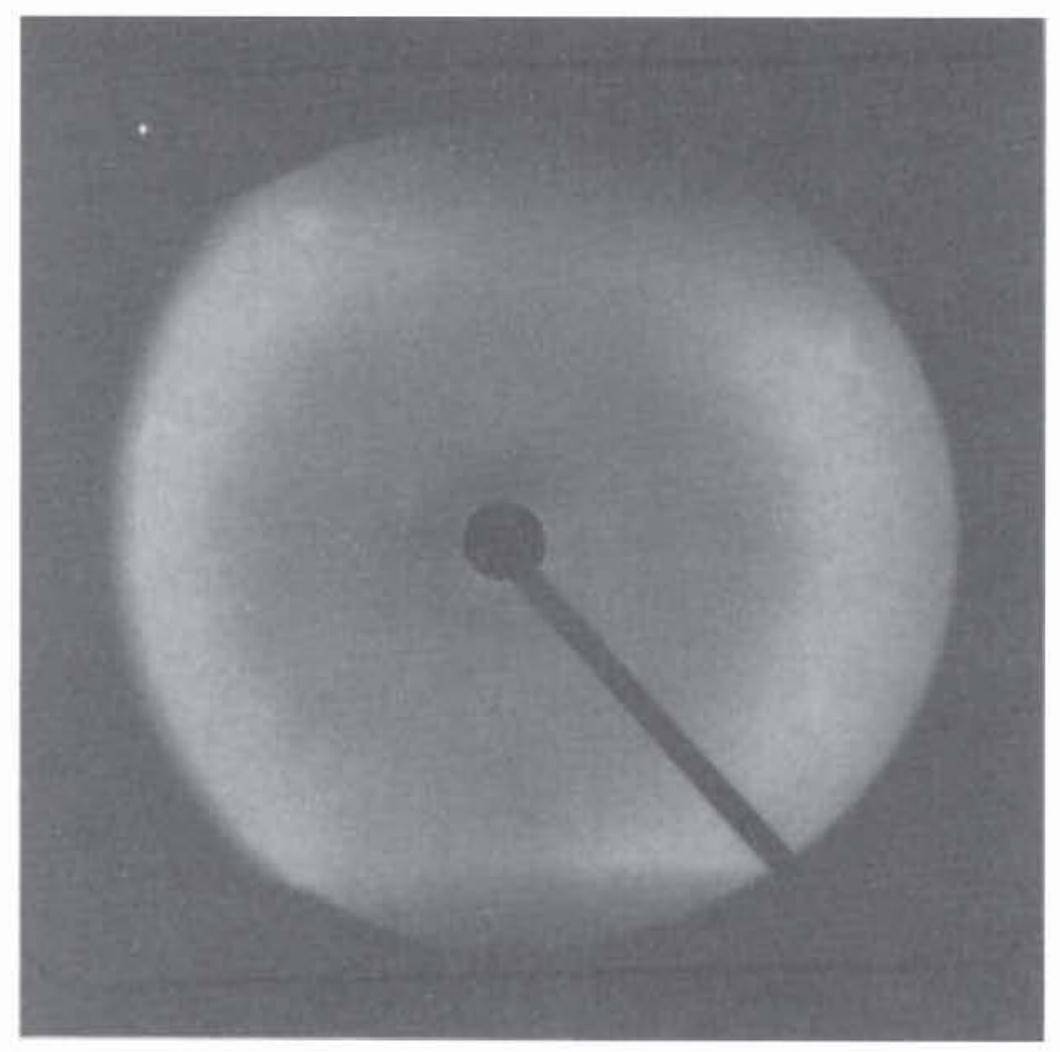

Figure 13. X-ray pattern of the nematic sample of PEt oriented in a magnetic field at $145^{\circ} \mathrm{C}$. The magnetic field direction is perpendicular to the X-ray beam, and is placed horizontal in this representation.

phase appears sometimes as Schlieren-texture (see figure 12), sometimes as homeotropic texture. The X-ray pattern of a magnetic field-aligned sample scarcely shows any orientation of the halo and the reflection are missing in the small angle region (figure 13).

The $\mathrm{S}_{\mathrm{A}}$ phase of $\mathrm{PBu}$ appears as focal-conic fan texture, and was obtained from the homoetropic nematic phase upon cooling (see figure 14). The $S_{A}$ phase of PEt, which originates from a nematic Schlieren-texture, shows a fan texture which is not fully developed (see figure 15). A clearly noticed change of texture takes place at the nematic- $S_{A}$ phase transition. The X-ray patterns of oriented smectic samples show the features of $\mathrm{S}_{\mathrm{A}}$ phases (see figure 16(a)). The meridional reflections are indicative of the layer thickness. They are sharp, and higher order reflections are present (see table 4). The halo, representing the packing of the side groups, lies centred on the equator.

Upon further cooling the texture remains unchanged when the sample becomes crystalline. The X-ray pattern of the crystalline phase resembles, with regard to position of reflections, i.e. the $d$-spacings, those of the corresponding $\mathrm{S}_{\mathrm{A}}$ phases (see figures $16(a)-(d))$. Only the diffuse equatorial reflections (haloes) in the smectic phase sharpen considerably in the crystalline state. These observations can be interpreted as an improvement of packing of the side groups without any changes in the thickness of the smectic layers.

D.S.C. measurements show, as well as polarization microscopic observations, a lesser supercooling of the polymers than for the corresponding monomers (see figure 17 and table 5), and the values for the transition enthalpies upon heating and cooling are in better agreement. 


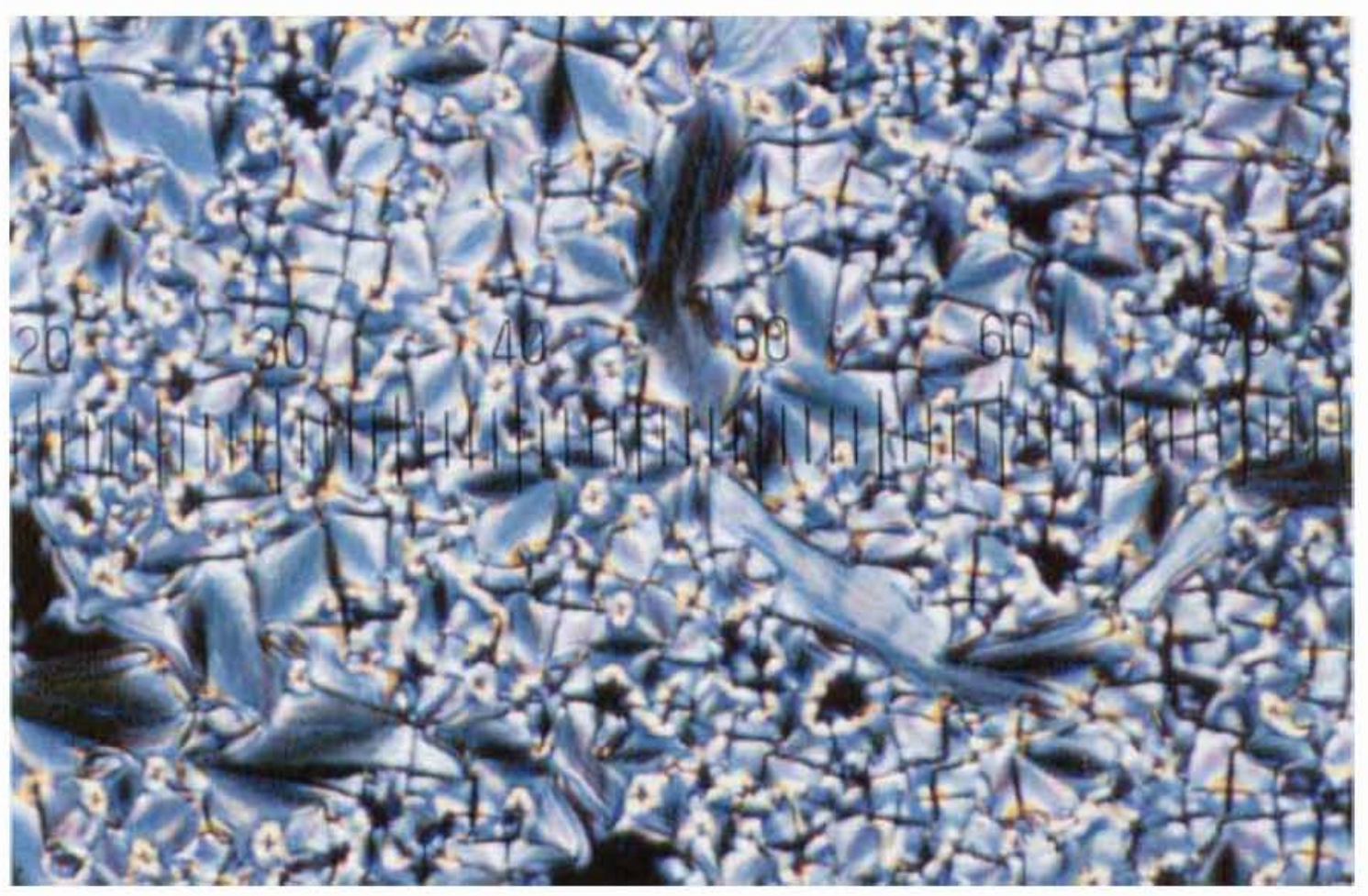

Figure 14. Fan-like textures of smectic $\mathrm{A}$ phase for $\mathrm{PBu}$ observed between crossed polars in the microscope $(\times 420)$ at $132^{\circ} \mathrm{C}$.

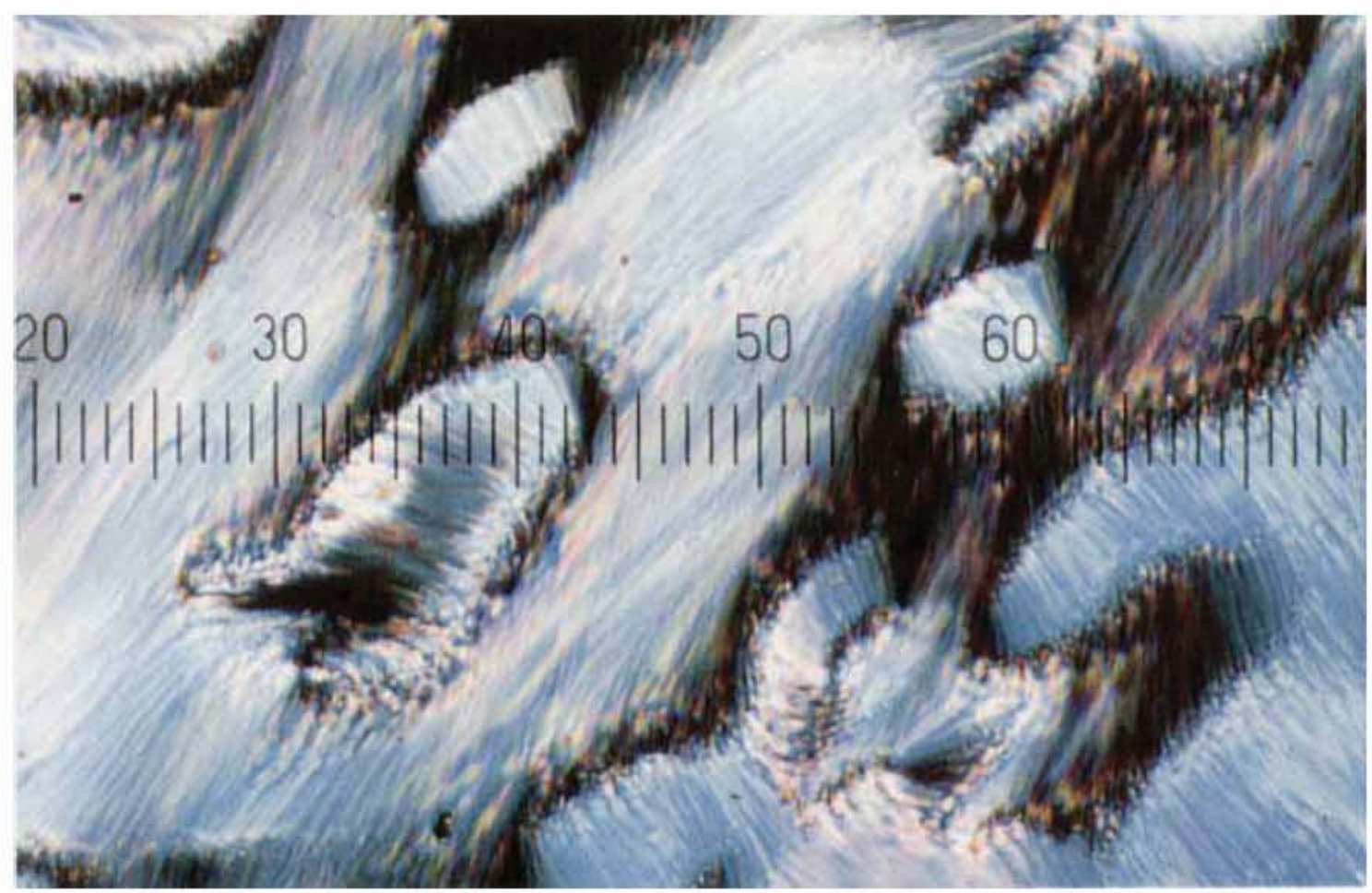

Figure 15. Fan-like texture, not fully developed, of smectic A phase for PET observed between crossed polars in the microscope $(\times 270)$ at $122 \cdot 6^{\circ} \mathrm{C}$. 

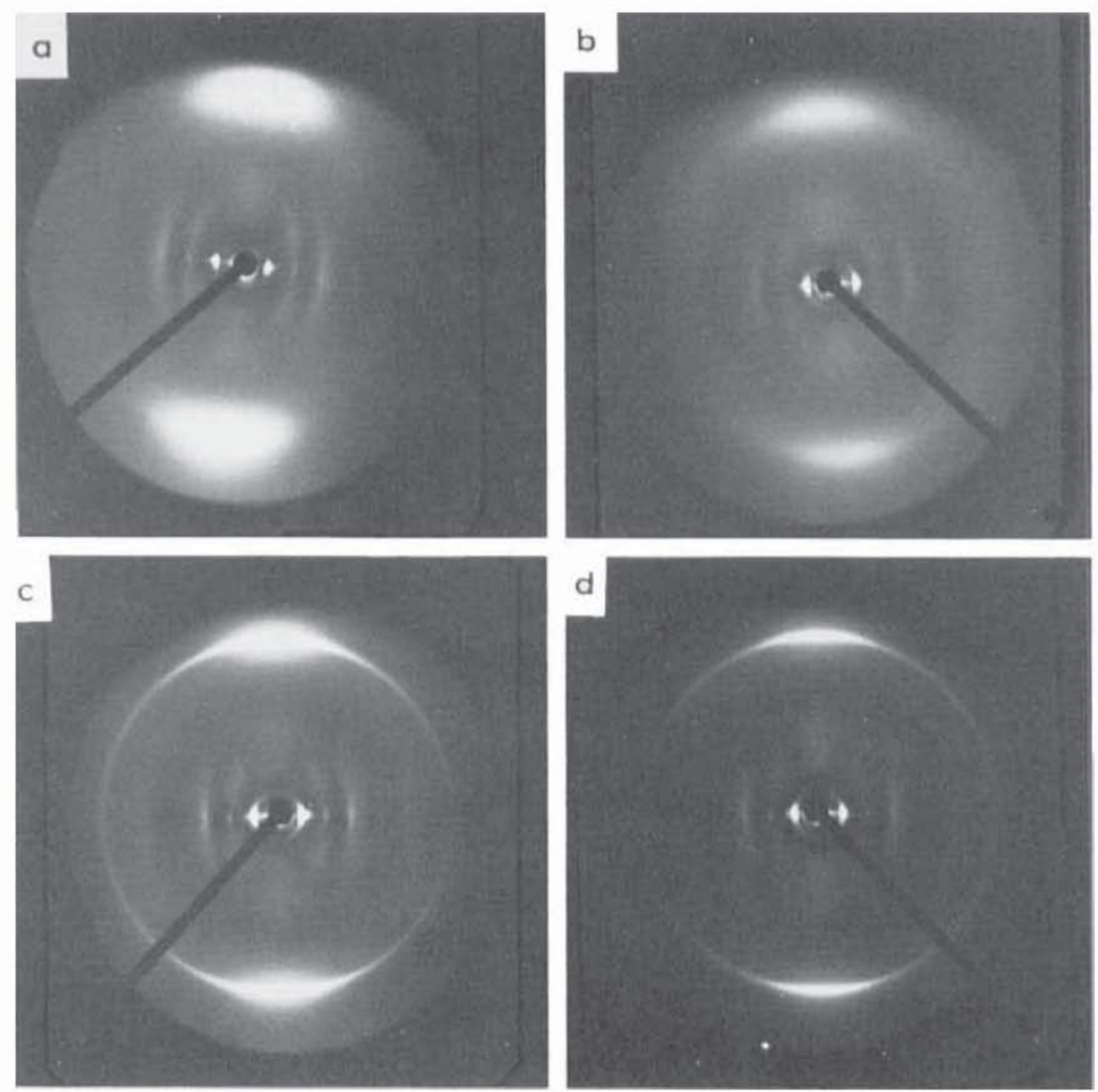

Figure 16. X-ray pattern of different polymeric samples all oriented in a magnetic field. The magnetic field direction is perpendicular to the X-ray beam, and is placed horizontal in this representation. The fibre axes correspond to magnetic field direction.) (a) Smectic A phase of PEt at $105^{\circ} \mathrm{C},(b)$ smectic A phase of $\mathrm{PBu}$ at $110^{\circ} \mathrm{C}$, (c) crystalline state of PEt at $25^{\circ} \mathrm{C}$ and $(d)$ crystalline state of $\mathrm{PBu}$ at $25^{\circ} \mathrm{C}$.

Table 4. $d$-Spacings of $\mathrm{X}$-ray exposures of magnetic field-oriented samples. The reflections $d_{1}, d_{2}$ and $d_{3}$ are placed on the meridian, the halo on the equator.

\begin{tabular}{lrccccc}
\hline Compound & $\vartheta /{ }^{\circ} \mathrm{C}$ & Phase & $d_{1} / \AA$ & $d_{2} / \AA$ & $d_{3} / \AA$ & $d_{\text {halo }} / \AA$ \\
\hline MEt & 80 & $\mathrm{~N}$ & $28 \cdot 0$ & - & $9 \cdot 3$ & $4 \cdot 5$ \\
$\mathrm{MBu}$ & 77 & $\mathrm{~N}$ & $29 \cdot 5$ & - & - & $4 \cdot 4$ \\
$\mathrm{MBu}$ & 76 & $\mathrm{~S}_{\mathrm{A}}$ & $30 \cdot 5$ & $15 \cdot 1$ & $9 \cdot 9$ & $4 \cdot 4$ \\
$\mathrm{PEt}$ & 145 & $\mathrm{~N}$ & - & - & - & $4 \cdot 4$ \\
$\mathrm{PEt}$ & 105 & $\mathrm{~S}_{\mathrm{A}}$ & $27 \cdot 5$ & $13 \cdot 8$ & $9 \cdot 1$ & $4 \cdot 4$ \\
$\mathrm{PEt}$ & 25 & $\mathrm{~K}$ & $27 \cdot 7$ & $13 \cdot 1$ & $9 \cdot 1$ & $4 \cdot 3$ \\
$\mathrm{PBu}$ & 131 & $\mathrm{~N}$ & - & - & - & $4 \cdot 4$ \\
$\mathrm{PBu}$ & 110 & $\mathrm{~S}$ & $29 \cdot 7$ & $15 \cdot 0$ & $9 \cdot 8$ & $4 \cdot 4$ \\
$\mathrm{PBu}$ & 25 & $\mathrm{~K}$ & $29 \cdot 7$ & $15 \cdot 0$ & $9 \cdot 8$ & $4 \cdot 4$ \\
\hline
\end{tabular}




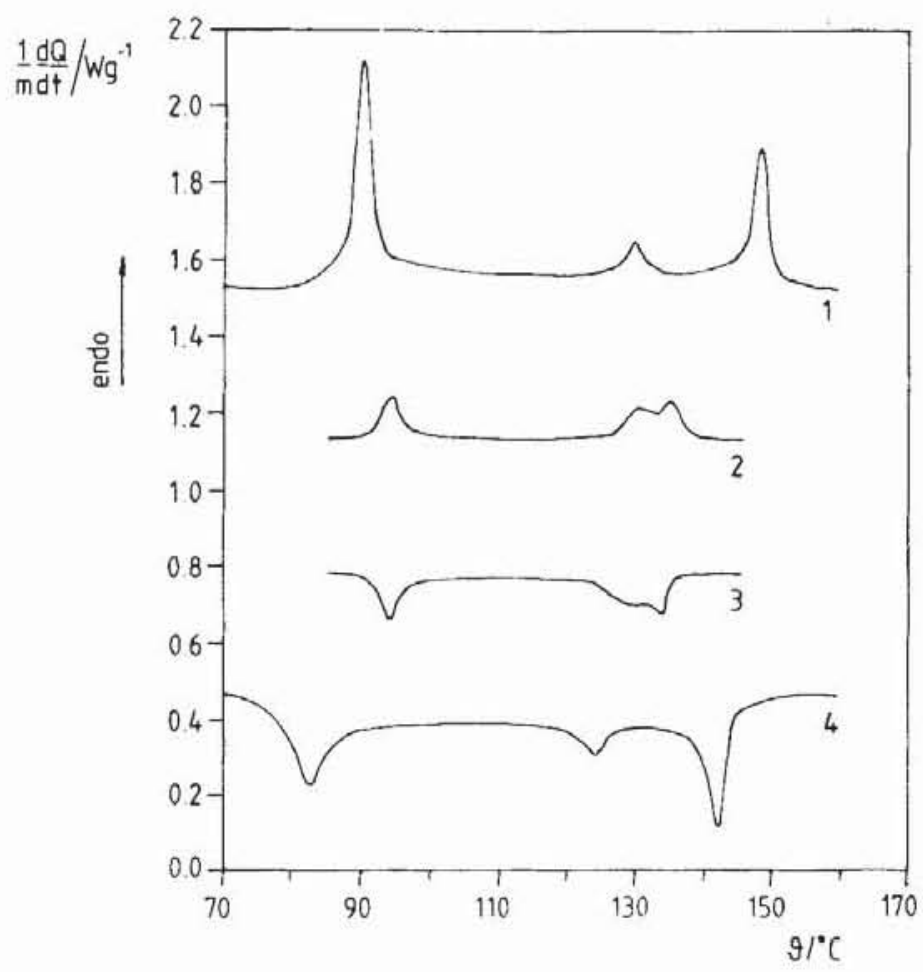

Figure 17. Normalized D.S.C. curves of the polymeric samples of PEt and PBu. 1, PEt upon heating at $20^{\circ} \mathrm{Cmin}^{-1}: 2, \mathrm{PBu}$ upon heating at $5^{\circ} \mathrm{Cmin}^{-1} ; 3, \mathrm{PBu}$ upon cooling at $5^{\circ} \mathrm{C} \mathrm{min}^{-1} ; 4$, PEt upon cooling at $20^{\circ} \mathrm{Cmin}^{-1}$.

Table 5. Temperature and enthalpy of the phase transitions of the polymers PEt and PBu from D.S.C. measurements.

\begin{tabular}{|c|c|c|c|c|c|}
\hline Compound & $\vartheta_{\text {onset }} /{ }^{\circ} \mathrm{C}$ & $\vartheta_{\text {peak }} /{ }^{\circ} \mathrm{C}$ & $\Delta H / \mathrm{Jg}^{-1}$ & Remarks & \\
\hline $\begin{array}{l}\text { PEt } \\
\text { PEt } \\
\text { PEt }\end{array}$ & $\begin{array}{r}87 \cdot 7 \\
127 \cdot 3 \\
146 \cdot 0\end{array}$ & $\begin{array}{r}90.0 \\
129 \cdot 6 \\
148.0\end{array}$ & $\begin{array}{l}8 \cdot 1 \\
1 \cdot 0 \\
3 \cdot 6\end{array}$ & $\left.\begin{array}{l}\mathrm{K} \rightarrow \mathrm{S}_{\mathrm{A}} \\
\mathrm{S}_{\mathrm{A}} \rightarrow \mathrm{N} \\
\mathrm{N} \rightarrow \mathrm{I}\end{array}\right\}$ & upon heating $\left(20^{\circ} \mathrm{Cmin}^{-1}\right)$ \\
\hline $\begin{array}{l}\text { PEt } \\
\text { PEt } \\
\text { PEt }\end{array}$ & $\begin{array}{r}144 \cdot 0 \\
126 \cdot 4 \\
88 \cdot 1\end{array}$ & $\begin{array}{r}142.2 \\
124.1 \\
82.5\end{array}$ & $\begin{array}{l}-3 \cdot 8 \\
-1 \cdot 2 \\
-8 \cdot 0\end{array}$ & $\left.\begin{array}{l}\mathrm{I} \rightarrow \mathrm{N} \\
\mathrm{N} \rightarrow \mathrm{S}_{\mathrm{A}} \\
\mathrm{S}_{\mathrm{A}} \rightarrow \mathrm{K}\end{array}\right\}$ & upon cooling $\left(20^{\circ} \mathrm{C} \mathrm{min}^{-1}\right)$ \\
\hline $\begin{array}{l}\mathrm{PBu} \\
\mathrm{PBu} \\
\mathrm{PBu}\end{array}$ & $\begin{array}{r}91 \cdot 6 \\
127 \cdot 4 \\
133 \cdot 1\end{array}$ & $\begin{array}{r}94 \cdot 3 \\
130 \cdot 5 \\
135 \cdot 1\end{array}$ & $\begin{array}{l}3 \cdot 7 \\
8 \cdot 6\end{array}$ & $\left.\begin{array}{l}\mathrm{K} \rightarrow \mathrm{S}_{\mathrm{A}} \\
\mathrm{S}_{\mathrm{A}} \rightarrow \mathrm{N} \\
\mathrm{N} \rightarrow \mathrm{I}\end{array}\right\}$ & upon heating $\left(5^{\circ} \mathrm{Cmin}^{-1}\right)$ \\
\hline $\begin{array}{l}\mathrm{PBu} \\
\mathrm{PBu} \\
\mathrm{PBu}\end{array}$ & $\begin{array}{r}134 \cdot 9 \\
131 \cdot 0 \\
96 \cdot 0\end{array}$ & $\begin{array}{r}133 \cdot 7 \\
129 \cdot 1 \\
93 \cdot 9\end{array}$ & $\left\{\begin{array}{l}-7 \cdot 7 \\
-3.8\end{array}\right.$ & $\left.\begin{array}{l}\mathrm{I} \rightarrow \mathrm{N} \\
\mathrm{N} \rightarrow \mathrm{S}_{\mathrm{A}} \\
\mathrm{S}_{\mathrm{A}} \rightarrow \mathrm{K}\end{array}\right\}$ & upon cooling $\left(5^{\circ} \mathrm{Cmin}^{-1}\right)$ \\
\hline
\end{tabular}

\subsection{Phase behaviour}

The results for the two slightly different monomeric benzylideneaniline compounds in comparison with the corresponding side group polymethacrylate can be summarized as follows.

(a) The two polymers investigated show the same sequence of phases in contrast to the monomeric compounds, which exhibit a different phase sequence. 
(b) The temperature intervals for the existence of liquid-crystalline phases is much broader for the polymers.

(c) The polymer PEt shows an $\mathrm{S}_{\mathrm{A}}$ phase which does not exist for the monomer MEt.

The polymer main chain, to which the side groups are attached, strongly influences the mesomorphy. New phases are formed and the liquid-crystalline temperature region are widened and stabilized.

It is interesting to compare the various transition enthalpies (see tables 3 and 5). The enthalpies of crystallization and melting for the polymers only amount to one-tenth of those of the monomers, all the other transitions showing comparable enthalpies in order of magnitude. This indicates that the formation of liquidcrystalline polymeric phases are primarly related by packing of the side groups, but that crystallization is mainly influenced or hindered by the main chains.

\subsection{Structure}

The $d$-spacing for the thickness of smectic A layers as determined by X-ray experiments of the monomeric compounds, MBu and MEt, agrees very well with that of the corresponding $d$-spacings for the layers of the polymers, PBu and PEt (see table 4). The difference in thickness between the two monomeric or polymeric compounds corresponds to the projected lengths of two methylene groups; i.e. $2 \cdot 5 \AA$, as expected. On the other hand, the layer thickness is in agreement with the lengths of an all-trans conformation for the monomeric molecule or for the side group of the polymer with the methyl group and size of the main chain added (see figure 18). The discussion of any structural model must thus account for

$$
d_{\text {monomer }} \approx d_{\text {polymer }} \approx L_{\text {molecule }} \text {. }
$$

Various packing models for liquid-crystalline side group polymers have been proposed as a two layer packing model, an antiparallel one layer and an antiparallel one layer with total overlapping pack-model [7]. A parallel one layer packing model with compensation of dipole moments is also feasible. This model and the one with antiparallel one layers with total overlapping can explain the experimentally established layer thickness of smectic and crystalline phases. However, a more thorough study will be necessary for a selection of one model or the other, since the very few reflections in the X-ray patterns are insufficient for a unique interpretation, and additional information will be needed.
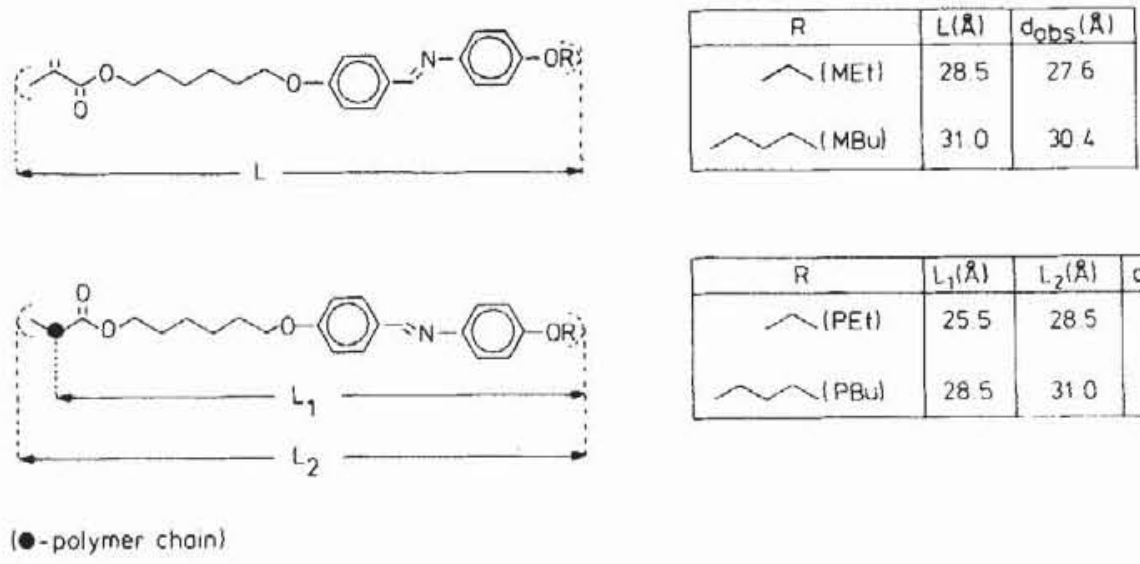

\begin{tabular}{|c|c|c|c|}
\hline$R$ & $L_{1}(R)$ & $L_{2}(R)$ & $d_{\text {Obs }}(A)$ \\
\hline$\sim$ (PEt) & 255 & 285 & 27.3 \\
$\sim$ (PBu) & 285 & 310 & 298 \\
\hline
\end{tabular}

Figure 18. Lengths of molecular models and observed $d$-spacings in X-ray diffraction experiments. 


\section{References}

[1] Perplies, E., Ringsdorf, H., and Wendorff, J., 1974, Makromolek. Chem., 175, 553.

[2] Clough, S. B., Blumstein, A., and De Vries, A., 1977, Polym. Preprints, $18,1$.

[3] Kostromin, S. G., Sinitzyn, V. V., Talroze, R. V., Shibaev, V. P., and Platé, N. A., 1982, Makromolek. Chem. rap. Commun., 3, 809.

[4] Talroze, R. V., Sinitzyn, V. V., Shibaev, V. P., and Platé, N. A., 1982, Molec. Crystals liq. Crystals, 80, 211.

[5] Gießelmann, F., 1988, Diploma Thesis, Institute of Physical Chemistry, Technische Universität, Clausthal-Zellerfeld.

[6] MüGge, J., and Zugenmaier, P., 1988, Molec. Crystals liq. Crystals, 155, 409.

[7] Shibaev, V. P., and Platé, N. A., 1984, Advances in Polymer Science 60/61, edited by M. Gordon and N. A. Platé (Springer-Verlag). 